\title{
The cause of autism and chronic disease: from misunderstanding to treatment, recovery, and prevention
}

\author{
Lisa Stephenson* \\ Canisius College, USA
}

\begin{abstract}
For three quarters of a century we have viewed autism as a psychiatric disorder with no known cause, no understanding of what is happening to the brains of affected individuals, no effective treatment, and no suggested prevention strategy. We now have 1 in 36 children living with autism, but the condition we call autism is not a psychiatric illness. The medical anatomy of autism and related disorders is now understood, and the cause of autism no longer remains a mystery.

Extensive clinical work over the past few years supports the hypothesis that our children are facing an immune-mediated disease that affects the central nervous system, which is the result of a multifactorial environmental assault, on genetically predisposed individuals, during a critical period of rapid development. The emerging body of evidence also demonstrates that autism and related neurological dysfunctions, along with infectious diseases, neurodegenerative disorders, and most non-communicable diseases (NCDs) are all symptoms of a dysregulated immune state, with microbiome depletion as the driving force behind this phenomenon.

The theme of this discussion is to develop a focus on the inter-relationship between the role of genetic predisposition, timing, and the environment in autism and chronic disease, and to lay the groundwork for the development of a treatment pipeline to assist those who have been injured. For the purposes outlined above, this discussion will focus mainly on autism since unravelling the medical underpinnings of this debilitating condition will effectively illuminate the underlying cause of almost every chronic condition, across the lifespan, and forge clear a path to an effective treatment and successful prevention protocol for a great number of chronic and debilitating diseases.
\end{abstract}

\section{Background}

For three quarters of a century we have viewed autism as a psychiatric disorder with no known cause, no understanding of what is happening to the brains of affected individuals, no effective treatment, and no suggested prevention strategy. We now have 1 in 36 children living with autism, but the condition we call autism is not a psychiatric illness. Autism is a set of symptoms of a dysfunctional immune system, caused by an environmental assault, from multiple triggers, on a genetically susceptible population during a critical period of rapid development. It is only when these three elements are working together in unison, creating a perfect storm, that a child will succumb to autism.

The theme of this discussion is to develop a focus on the interrelationship between genetic predisposition, timing, and the environment in autism and chronic disease, and lay the groundwork for the development of a treatment pipeline that must be implemented immediately in order to halt the progression of this silent and insidious pandemic of modern culture. For the purposes outlined above, this discussion will focus mainly on autism since unravelling the medical underpinnings of this debilitating condition will effectively illuminate the underlying cause of almost every chronic condition, across the lifespan, and forge a clear path to an effective treatment and successful prevention protocol for a great number of chronic and debilitating diseases, including the conditions that are presently believed to be mental disorders.

Dr. Michael J. Goldberg, M.D. and Director of the NIDS Research Institute, has been successfully treating children with autism, ADHD, and related disorders for over twenty-five years. Dr. Goldberg theorized many years ago that chronic pediatric neurological dysfunctions are symptoms of a compromised immune system. He refers to them as Neuro-Immune Dysfunction Syndromes, or NIDS. Dr. Goldberg's work began in the 1980's with Chronic Fatigue Syndrome (CFS), also known as Chronic Fatigue Immune Dysfunction Syndrome (CFIDS) or Myalgic Encephalomyelitis (ME), when his wife was stricken with this mysterious illness. Dr. Goldberg is now working with professionals around the globe to have autism, Attention Deficit/Hyperactivity Disorder (ADHD), Obsessive Compulsive Disorder (OCD), CFS/ CFIDS/ME and other chronic neurological disorders recognized as phenotypic expressions of an underlying auto-immune/neuroimmune disease process.

\section{The cause of autism}

The history of autism has been marred by vehement discourse within the community itself, unsubstantiated theories of causation, and a hopeless search for answers. By the turn of the century, a heated controversy surrounding vaccines and autism transpired, due to an article published in 1998 that linked the combined measles, mumps, and rubella vaccine to ulcerative colitis and autism spectrum disorders. The paper was deemed to be fraudulent but the belief that vaccines cause autism in children persists today. The study, which has since

${ }^{*}$ Correspondence to: Lisa Stephenson, Canisius College, USA, E-mail: lstephenson137@gmail.com

Key words: autism spectrum disorders, chronic disease, environment, epigenetics, immune system, microbiome

Received: September 28, 2018; Accepted: October 08, 2018; Published: October 11,2018 
been retracted, lead to a decline in vaccination rates across the globe and a resurgence of measles and mumps, resulting in deaths and serious permanent injuries. ${ }^{1}$ This, in turn, prompted hundreds of studies around the world involving millions of children to dispute the consensus that vaccines play a causal role in the development of autism.

There is absolutely no verifiable proof that vaccines cause autism but the reason some children develop autism following a vaccination is now clear, and it does not lie with the vaccine itself. The culprit now appears to be acetaminophen, or Tylenol ${ }^{\circ}$, which is widely used during pregnancy and is routinely administered prior to and following vaccinations in babies and young children to alleviate pain. ${ }^{2}$ Acetaminophen, also known as paracetamol, overloads the sulfur metabolism pathway leading to an overproduction of $\mathrm{N}$-acetyl-p-benzoquinone imine, a toxic by-product produced during acetaminophen metabolism. Consequently, immune function is suppressed and the liver's supply of glutathione is depleted, reducing the body's ability to detoxify environmental toxins, thereby increasing oxidative stress, which leads to protein, lipid, and nucleic acid damage from free radicals. Being the body's main antioxidant, glutathione is vital for healthy immune function, controlling inflammation, and disease prevention. One of the characteristic effects of excess acetaminophen usage is loss of Purkinje cells in the brain, consistent with findings in autism, ${ }^{3}$ and Bauer and Kriebel found that when acetaminophen became commonly used to treat circumcision pain after 1995, there was a strong correlation between country-level autism prevalence in males and a country's circumcision rate. ${ }^{4}$ In fact, it is now hypothesized that the epidemic rates of autism, asthma, and ADHD throughout much of the world may be largely due to the increased use of acetaminophen during pregnancy and in genetically and/or metabolically susceptible children, since the marked increase in chronic pediatric disease coincides with the replacement of aspirin by acetaminophen in the 1980s, after aspirin was implicated in the development of Reye's syndrome. ${ }^{5}$

The medical anatomy of autism and related disorders has now gained definition and the cause of autism no longer remains a mystery. Extensive clinical work over the past few years supports the hypothesis

${ }^{1}$ McIntyre P, Leask J. Improving uptake of MMR vaccine. BMJ : British Medical Journal. 2008;336(7647):729-730. doi:10.1136/bmj.39503.508484.80.

${ }^{2}$ William Shaw. Evidence that Increased Acetaminophen use in Genetically Vulnerable Children Appears to be a Major Cause of the Epidemics of Autism, Attention Deficit with Hyperactivity, and Asthma. Journal of Restorative Medicine, Volume 2, Number 1, 1 October 2013, pp. 14-29(16), Schultz ST, Klonoff-Cohen HS, Wingard DL, et al. Acetaminophen (paracetamol) use, measles-mumps-rubella vaccination, and autistic disorder: the results of a parent survey. Autism. 2008 May;12(3):293-307. doi: 10.1177/1362361307089518, Peter Good. Did Acetaminophen Provoke the Autism Epidemic? Alternative Medicine Review. Volume 14, Number 4 2009, Schultz ST, Klonoff-Cohen HS, Wingard DL, et al. Acetaminophen (paracetamol) use, measles-mumps-rubella vaccination, and autistic disorder: the results of a parent survey. Autism. 2008 May;12(3):293-307. doi: $10.1177 / 1362361307089518$, Schultz ST. Can autism be triggered by acetaminophen activation of the endocannabinoid system? Acta Neurobiol Exp (Wars). 2010;70(2):227-31.

${ }^{3}$ Lotta LT, Conrad K, Cory-Slechta D, Schor NF. Cerebellar Purkinje cell p75 neurotrophin receptor and autistic behavior. Translational Psychiatry. 2014;4(7):e416-. doi:10.1038/ tp.2014.55.

${ }^{4}$ Bauer AZ, Kriebel D. Prenatal and perinatal analgesic exposure and autism: an ecological link. Environ Health. 2013 May 9;12:41. doi: 10.1186/1476-069X-12-41.

${ }^{5}$ Brandlistuen RE, Ystrom E, Nulman I, et al. Prenatal paracetamol exposure and child neurodevelopment: a sibling-controlled cohort study. Int J Epidemiol. 2013 Dec;42(6):1702-13. doi: 10.1093/ije/dyt183. Epub 2013 Oct 24, Vlenterie R, Wood ME, Brandlistuen RE, et al. Neurodevelopmental problems at 18 months among children exposed to paracetamol in utero: a propensity score matched cohort study. International Journal of Epidemiology. 2016;45(6):1998-2008. doi:10.1093/ije/dyw192, Magnus MC, Karlstad Ø, Håberg SE, et al. Prenatal and infant paracetamol exposure and development of asthma: the Norwegian Mother and Child Cohort Study. Int J Epidemiol. 2016 Apr;45(2):512-22. doi: 10.1093/ije/ dyv366. Epub 2016 Feb 9. that our children are facing an immune-mediated disease that affects the central nervous system, which is the result of a multifactorial environmental assault, on genetically predisposed individuals, during a critical period of development. The emerging body of evidence also demonstrates that autism and related neurological dysfunctions, along with infectious diseases, neurodegenerative disorders and most non-communicable diseases (NCDs) are symptoms of a dysregulated immune state, with microbiome depletion as the driving force behind this phenomenon.

\section{The human microbiome: at the root of chronic disease}

The human gastrointestinal tract is host to a complex and dynamic population of microorganisms, the gut microbiota, that impart important functions in host nutrient metabolism and energy production, xenobiotic and drug metabolism, immune cell development, maintaining epithelial intestinal barrier homeostasis, immunomodulation and protection against pathogens. Collectively known as the human microbiome, the microbiota consists of a wide range of pathogens, commensals and mutualists, and approximately ten times more bacterial cells than human cells. Microbial diversity is intrinsic to healthy immune maturation and function, and normal microbiota development is contingent upon acquiring the right microbes in the right order during critical windows of childhood growth. The microbiome is essentially the foundation for all body functions and it is now well established that a healthy microbiome is largely responsible for overall health of the host.

The human microbiome is one of the densest microbial communities on earth and has a massive influence over the human body, affecting cellular activity, immune function and switching our genes on and off. ${ }^{6}$ It now appears that the microbiome is the ultimate stimulus for epigenetic processes, because it is the first point of contact with environmental and dietary influences before they reach human cells, thereby influencing gene expression linked to certain disease, such as cancer. ${ }^{7}$ The composition of microbiota that humans harbour throughout their lifetime is established during the first few years of life. Microbial colonization, or the seeding of our core microbiota, occurs parallel with immune system maturation and synaptic development, which takes about three years. ${ }^{8}$ Similarly, a decline in microbiota richness and diversity with aging has been evidenced to occur parallel with a decrease in neuronal complexity and immunocompetence. ${ }^{9}$ Research has now established that the intestinal microbiota must be populated within the early developmental window of life, in order to facilitate the microbiota's role in protecting epithelial barrier integrity, regulating inflammation, modulating immune function, influencing circadian rhythm, programming the hypothalamic-pituitary-adrenal axis, or stress response system, and supporting normal synaptogenesis. ${ }^{10}$

\footnotetext{
${ }^{6}$ Carbonero F. Human epigenetics and microbiome: the potential for a revolution in both research areas by integrative studies. Future Science OA. 2017;3(3):FSO207. doi:10.4155/ fsoa-2017-0046.

${ }^{7}$ Hullar MAJ, Fu BC. Diet, the Gut Microbiome, and Epigenetics. Cancer journal (Sudbury, Mass). 2014;20(3):170-175. doi:10.1097/PPO.0000000000000053.

${ }^{8}$ Rodríguez JM, Murphy K, Stanton C, et al. The composition of the gut microbiota throughout life, with an emphasis on early life. Microbial Ecology in Health and Disease. 2015;26:10.3402/mehd.v26.26050. doi:10.3402/mehd.v26.26050.

${ }^{9}$ E. Biagi, M. Candela, S. Fairweather-Tait, et al. Aging of the human metaorganism: the microbial counterpart. Age (Dordr), 34 (1) (2012), pp. 247-267, Claesson MJ1, Jeffery IB, Conde S, et al. Gut microbiota composition correlates with diet and health in the elderly. Nature. 2012 Aug 9;488(7410):178-84. doi: 10.1038/nature11319.

${ }^{10}$ Kieran Rea, Timothy G. Dinan, John F. Cryan. The microbiome: A key regulator of stress and neuroinflammation. Neurobiology of Stress. V. 4, Oct. 2016, Pages 23-33,
} 
Microbiome depletion and declining pathogen resistance is now implicated in a large and ever-increasing number of neurologic, gastrointestinal, metabolic, oncologic, hepatic, cardiovascular, psychologic, respiratory, and autoimmune disorders. ${ }^{11} \mathrm{~A}$ number of environmental factors have been recognized as causal factors in this phenomenon including antibiotics, pesticides, ${ }^{12}$ air pollutants, ${ }^{13}$ PCBs,${ }^{14}$ heavy metals, ${ }^{15}$ and diet. A growing body of research also now shows that proton pump inhibitors, one of the most widely used classes of drugs, are more effective at altering microbiota composition than antibiotics. ${ }^{16}$

Maintaining the structure of the epithelial gut lining is of critical importance and without a properly colonized microbiome, the epithelial barrier may become compromised and induce profound systemic damage. The main functions of the intestinal epithelial barrier are to regulate the absorption of nutrients, electrolytes, and water, and to prevent the entry of toxins and pathogenic microorganisms. To maintain these functions, microbial equilibrium is required. Perturbations of the microbiome and intestinal barrier dysfunction have been demonstrated in autoimmune disease, obesity, metabolic diseases, and in individuals with autism and their firstdegree relatives. ${ }^{17}$ The intestinal microbiota plays an important role

Heijtz RD, Wang S, Anuar F, et al. Normal gut microbiota modulates brain development and behavior. Proceedings of the National Academy of Sciences of the United States of America. 2011;108(7):3047-3052. doi:10.1073/pnas.1010529108, Sudo N, Chida Y, Aiba $\mathrm{Y}$, et al. Postnatal microbial colonization programs the hypothalamic-pituitary-adrenal system for stress response in mice. The Journal of Physiology. 2004;558(Pt 1):263-275. doi:10.1113/jphysiol.2004.063388, Clarke, G. et al. (2013) The microbiome-gut-brain axis during early life regulates the hippocampal serotonergic system in a sex- dependent manner. Mol. Psychiatry 18, 666-673, Yuliya E. Borre, Gerard W. O'Keeffe, Gerard Clarke. Microbiota and neurodevelopmental windows: implications for brain disorders. Trends in Molecular Medicine. Volume 20, Issue 9, September 2014, Pages 509-518, de Theije CG, Wopereis H, Ramadan M, et al. Altered gut microbiota and activity in a murine model of autism spectrum disorders. Brain Behav Immun. 2014 Mar;37:197-206. doi: 10.1016/j. bbi.2013.12.005. Epub 2013 Dec 11, S.M. O’Mahony, G. Clark, T.G. Dinanbc, J.F. Cryanab. Early-life adversity and brain development: Is the microbiome a missing piece of the puzzle? Neuroscience. Volume 342, 7 February 2017, Pages 37-54, Leone V., Gibbons S.M., Martinez K. Effects of diurnal variation of gut microbes and high-fat feeding on hos circadian clock function and metabolism. Cell Host Microbe. 2015;17:681-689.

${ }^{11}$ Susan V. Lynch, and Oluf Pedersen. The Human Intestinal Microbiome in Health and Disease. N Engl J Med 2016; 375:2369-2379 December 15, 2016

${ }^{12}$ Liu Q, Shao W, Zhang C, et al. Organochloride pesticides modulated gut microbiota and influenced bile acid metabolism in mice.

\section{Environ Pollut. 2017 Jul;226:268-276. doi: 10.1016/j.envpol.2017.03.068. Epub 2017 Apr 6.}

${ }^{13}$ Salim SY, Kaplan GG, Madsen KL. Air pollution effects on the gut microbiota: A link between exposure and inflammatory disease. Gut Microbes. 2014;5(2):215-219. doi:10.4161/ gmic. 27251 .

${ }^{14}$ Kohl KD, Cary TL, Karasov WH, Dearing MD. Larval exposure to polychlorinated biphenyl 126 (PCB-126) causes persistent alteration of the amphibian gut microbiota. Environ Toxicol Chem. 2015 May;34(5):1113-8. doi: 10.1002/etc.2905. Epub 2015 Apr 7.

${ }^{15}$ Breton J, Massart S, Vandamme P, De Brandt E, Pot B, Foligné B. Ecotoxicology inside the gut: impact of heavy metals on the mouse microbiome. BMC Pharmacology \& Toxicology. 2013;14:62. doi:10.1186/2050-6511-14-62.

${ }^{16}$ Imhann F, Vich Vila A, Bonder MJ, et al. The influence of proton pump inhibitors and other commonly used medication on the gut microbiota. Gut Microbes. 2017;8(4):351-358. doi:10.1080/19490976.2017.1284732, Takagi T, Naito Y, Inoue R, et al. The influence of long-term use of proton pump inhibitors on the gut microbiota: an age-sex-matched case-control study. Journal of Clinical Biochemistry and Nutrition. 2018;62(1):100-105. doi:10.3164/jcbn.17-78, Hojo M, Asahara T, Nagahara A, et al. Gut Microbiota Composition Before and After Use of Proton Pump Inhibitors. Dig Dis Sci. 2018 May 24. doi: 10.1007/s10620-018-5122-4, Imhann F, Bonder MJ, Vich Vila A, et al. Proton pump inhibitors affect the gut microbiome. Gut. 2016 May;65(5):740-8. doi: 10.1136/gutjnl-2015-310376. Epub 2015 Dec 9.

${ }^{17}$ Lin R, Zhou L, Zhang J, Wang B. Abnormal intestinal permeability and microbiota in patients with autoimmune hepatitis. Int J Clin Exp Pathol (2015) 8(5):5153-60, Fasano A. Zonulin, regulation of tight junctions, and autoimmune diseases. Ann N Y Acad Sci (2012) in pathogen resistance, both by direct interaction with pathogenic microbes and also by influencing the immune system. ${ }^{18}$ When faced with adverse conditions, such as exposure to pathogens, environmental toxins, stress, or lack of nutrition, an unbalanced microbiome is unable to carry out its functions. A large body of literature now shows that microbiota alterations, intestinal permeability, and inflammation play a central role in the development of mental disorders and chronic disease. ${ }^{19}$ Post-industrial society and modern lifestyles have profoundly eradicated key components of the microbiome, minimizing optimal function and reducing it to an unstable, inflammatory, and diseaseprone state. A recent metagenomic study of eighteen skin sites in fifteen

1258:25-33.10.1111/j.1749-6632.2012.06538.x, Khaleghi S, Ju JM, Lamba A, Murray JA. The potential utility of tight junction regulation in celiac disease: focus on larazotide acetate. Therap Adv Gastroenterol (2016) 9(1):37-49.10.1177/1756283X15616576, Fasano A, Shea-Donohue T. Mechanisms of disease: the role of intestinal barrier function in the pathogenesis of gastrointestinal autoimmune diseases. Nat Clin Pract Gastroenterol Hepatol (2005) 2(9):416-22.10.1038/ncpgasthep0259, Tlaskalova-Hogenova H, Stepankova R, Kozakova $\mathrm{H}$, et al. The role of gut microbiota (commensal bacteria) and the mucosal barrier in the pathogenesis of inflammatory and autoimmune diseases and cancer: contribution of germ-free and gnotobiotic animal models of human diseases. Cell Mol Immunol (2011) 8(2):110-20.10.1038/cmi.2010.67, Bergheim I, Weber S, Vos M, et al. Antibiotics protect against fructose-induced hepatic lipid accumulation in mice: role of endotoxin. $J$ Hepatol. 2008, 48: 983-992, Thuy S, Ladurner R, Volynets V, et al. Nonalcoholic fatty liver disease in humans is associated with increased plasma endotoxin and plasminogen activator inhibitor 1 concentrations and with fructose intake. J Nutr. 2008, 138: 1452-1455, de Magistris L, Familiari V, Pascotto A, et al. Alterations of the intestinal barrier in patients with autism spectrum disorders and in their first-degree relatives. J Pediatr Gastroenterol Nutr. 2010 Oct;51(4):418-24. doi: 10.1097/MPG.0b013e3181dcc4a5, Souza NC, Mendonca JN, Portari GV, et al. Intestinal permeability and nutritional status in developmental disorders.

\section{Altern Ther Health Med. 2012 Mar-Apr;18(2):19-24.}

${ }^{18}$ Tlaskalová-Hogenová H, Stěpánková R, Kozáková H, et al. The role of gut microbiota (commensal bacteria) and the mucosal barrier in the pathogenesis of inflammatory and autoimmune diseases and cancer: contribution of germ-free and gnotobiotic animal models of human diseases. Cell Mol Immunol. 2011;8:110-20. doi: 10.1038/cmi.2010.67, Turner JR. Intestinal mucosal barrier function in health and disease. Nat Rev Immunol. 2009;9:799-809.

${ }^{19}$ Dantzer R, O'Connor JC, Freund GG, Johnson RW, Kelley KW. From inflammation to sickness and depression: when the immune system subjugates the brain. Nature reviews Neuroscience. 2008;9(1):46-56. doi:10.1038/nrn2297, Patel A. Review: the role of inflammation in depression. Psychiatr Danub. 2013 Sep;25 Suppl 2:S216-23, Verdam FJ, Fuentes $\mathrm{S}$, de Jonge $\mathrm{C}$ et al. Human intestinal microbiota composition is associated with local and systemic inflammation in obesity. Obesity (Silver Spring). 2013 Dec;21(12):E607-15. doi: 10.1002/oby.20466. Epub 2013 Jun 22, Maes M, Kubera M, Leunis JC, Berk M: Increased IgA and IgM responses against gut commensals in chronic depression: further evidence for increased bacterial translocation or leaky gut. J Affect Disord. 2012, 141: 55-62. 10.1016/j. jad.2012.02.023, Maes M, Kubera M, Leunis JC, Berk M, Geffard M, Bosmans E: In depression, bacterial translocation may drive inflammatory responses, oxidative and nitrosative stress (O\&NS), and autoimmune responses directed against O\&NS-damaged neoepitopes. Acta Psychiatr Scand. 2013, 127: 344-354. 10.1111/j.1600-0447.2012.01908.x, Leclercq $\mathrm{S}$, Cani PD, Neyrinck AM, et al. Role of intestinal permeability and inflammation in the biological and behavioral control of alcohol-dependent subjects. Brain Behav Immun. 2012 26: 911-918. 10.1016/j.bbi.2012.04.001, Teixeira TF, Souza NC, Chiarello PG, et al. Intestinal permeability parameters in obese patients are correlated with metabolic syndrome risk factors. Clin Nutr. 2012, 31: 735-740. 10.1016/j.clnu.2012.02.009, Goebel A, Buhner S, Schedel R, Lochs H, Sprotte G. Altered intestinal permeability in patients with primary fibromyalgia and in patients with complex regional pain syndrome. Rheumatology. 2008, 47: 1223-1227. 10.1093/rheumatology/ken140, Maes M, Twisk FN, Kubera M, et al. Increased IgA responses to the LPS of commensal bacteria is associated with inflammation and activation of cell-mediated immunity in chronic fatigue syndrome. $J$ Affect Disord. 2012, 136: 909-917, Kivimäki M, Shipley MJ, Batty GD, et al. Long-term inflammation increases risk of common mental disorder: a cohort study. 2013, doi: 10.1038/mp.2013.35, Q. Li, J.-M. Zhou. The microbiota-gut-brain axis and its potential therapeutic role in autism spectrum disorder. Neuroscience. Volume 324, 2016, Pages 131-139, Anastasia I. Petra, Smaro Panagiotidou, Erifili Hatziagelaki, et al. Gut-Microbiota-Brain Axis and Its Effect on Neuropsychiatric Disorders With Suspected Immune Dysregulation. Clinical Therapeutics. Volume 37, Issue 5, 2015, Pages 984-995, Francesca Mangiola, Gianluca Ianiro, Francesco Franceschi, et al. Gut microbiota in autism and mood disorders. World J Gastroenterol. Jan 7, 2016; 22(1): 361-368. Published online Jan 7, 2016. doi: 10.3748/ wjg.v22.i1.361, Slattery J, MacFabe DF, Frye RE. The Significance of the Enteric Microbiome on the Development of Childhood Disease: A Review of Prebiotic and Probiotic Therapies in Disorders of Childhood. Clinical Medicine Insights Pediatrics. 2016;10:91107. doi:10.4137/CMPed.S38338. 
healthy adults revealed that only about $30 \%$ of microbial functional gene content was maintained across body sites. ${ }^{20}$ The dramatic increase in melanoma and squamous- and basal-cell carcinomas is very likely a consequence of skin microbiome depletion, and not due to the direct exposure to ultraviolet radiation itself.

The failure to support early-life microbiome development and the consequential downward shift of healthy microbiota in the human microbiome plays a direct role in the epidemic increase of chronic disease states across all nations. Consumption of the Western diet, compounded by exposure to a wide range of environmental stressors, undermines optimal nutritional and the evolutionary principals of our past and fosters the growth of pathogenic flora. This dysregulation of the most important physiological network in the human body has undeniably destabilized the immune system at a population-wide level and has given rise to a profound neuroimmune epiphenomena.

\section{The role of the immune system, microglial activation and meningeal lymphatic vessels in autism and chronic disease}

Human Immunodeficiency Virus (HIV) first appeared in the U.S. as early as 1960, but it was not until 1981 that the first patient was formally diagnosed. The AIDS epidemic gripped the world with illness, fear and death but the scientific advances achieved in HIV and Simian Immunodeficiency Virus (SIV) research fostered our understanding of the mechanisms relating to the structural and immunological damage to the gastrointestinal tract during the initial acute phase of infection, the pathological immune activation during the chronic phase, and effectively established the underlying cause of AIDS, autism and the many, many immune related disease states that children and adults face today.

During the initial acute phase of HIV infection, patients present with gastrointestinal pathology, rapid and substantial damage to gutassociated lymphatic tissues, and immune activation characterized by massive depletion of Th17 cells, a subset of CD4+ T cells that control intestinal bacteria, ${ }^{21}$ polyclonal $\mathrm{B}$-cell activation, ${ }^{22}$ increased $\mathrm{T}$-cell turnover ${ }^{23}$ increased frequencies of $\mathrm{T}$-cells, ${ }^{24}$ and increased serum levels of proinflammatory cytokines and chemokines. ${ }^{25}$ Moreover, genes associated with cell cycle regulation, lipid metabolism, and epithelial cell barrier and digestive functions are downregulated, as evidenced in gene expression profiles of GI tract biopsies from HIVinfected individuals. ${ }^{26}$ The damage incurred during the initial infection

${ }^{20}$ Oh J, Byrd AL, Park M. NISC Comparative Sequencing Program, Kong HH, Segre JA. Temporal Stability of the Human Skin Microbiome. Cell. 2016;165(4):854-866. doi:10.1016/j.cell.2016.04.008.

${ }^{21}$ Guadalupe M, Reay E, Sankaran S, et al. Severe CD4+ T-cell depletion in gut lymphoid tissue during primary human immunodeficiency virus type 1 infection and substantial delay in restoration following highly active antiretroviral therapy. J Virol. $2003 \mathrm{Nov}$; 77(21):11708-17.

${ }^{22}$ Lane HC, Masur H, Edgar LC, et al. Abnormalities of B-cell activation and immunoregulation in patients with the acquired immunodeficiency syndrome. $N$ Engl J Med. $1983 \mathrm{Aug}$ $25 ; 309(8): 453-8$.

${ }^{23}$ Hellerstein M, Hanley MB, Cesar D, et al. Directly measured kinetics of circulating T lymphocytes in normal and HIV-1-infected humans. Nat Med. 1999 Jan; 5(1):83-9.

${ }^{24}$ Hazenberg $M D$, Stuart JW, Otto SA, et al. T-cell division in human immunodeficiency virus (HIV)-1 infection is mainly due to immune activation: a longitudinal analysis in patients before and during highly active antiretroviral therapy (HAART). Blood. 2000 Jan 1; 95(1):249-55.

${ }^{25}$ Valdez H, Lederman MM. Cytokines and cytokine therapies in HIV infection. AIDS Clin Rev. 1997-1998; ():187-228.

${ }^{26}$ Sankaran S, Guadalupe M, Reay E, et al. Gut mucosal T cell responses and gene expression correlate with protection against disease in long-term HIV-1-infected nonprogressors. Proc Natl Acad Sci USA. 2005;102:9860-9865. stage causes intestinal permeability and concomitant microbial translocation. Tissue analysis reveals that the bacteria moving out of the gut lumen, into the lamina propria, to the lymph nodes, and beyond into non-lymphatic tissues and organs, ${ }^{27}$ is the primary cause of pathological immune activation in HIV/SIV. ${ }^{28}$ This damage to the GI tract adversely impacts nutrient adsorption and digestive functions, with the potential to reduce the efficacy of antiretroviral therapy. Consequently, symptoms of initial phase infection that continue throughout disease progression include diarrhea, increased gastrointestinal inflammation, increased intestinal permeability (up to five-fold higher than healthy controls) and malabsorption of bile acids and vitamin $\mathrm{B} 12 .^{29}$

In the advanced HIV infection stage, the homeostatic balance between the microbiota and intestinal immunity fails and microbes are able to penetrate the intestinal barrier and gain systemic circulation. Following considerable structural and immunological damage to the gastrointestinal system, this phase of HIV/SIV infection is marked by a persistent inflammatory response by the immune system as a direct consequence of translocation of microbial products from the lumen of the GI tract into the system..$^{30}$ The degree of inflammation within the GI tract correlates with viral replication ${ }^{31}$ and a higher degree of microbial translocation corelates with a higher level of immunodeficiency. ${ }^{32}$ It is also important to note that the extent of the dysfunction can better predict disease progression than clinical biomarkers. ${ }^{33}$ The progression to AIDS is then defined by viral replication and a slow, continuous depletion of $\mathrm{CD}^{+} \mathrm{T}$-cells, eventually rendering the host defenseless to other opportunistic pathogens and toxic environmental assaults.

${ }^{27}$ Brenchley JM, Schacker TW, Ruff LE, et al. CD4+ T cell depletion during all stages of HIV disease occurs predominantly in the gastrointestinal tract. The Journal of experimental medicine. 2004;200:749-759.

${ }^{28}$ Brenchley JM, Price DA, Schacker TW, et al. Microbial translocation is a cause of systemic immune activation in chronic HIV infection. Nat Med. 2006 Dec; 12(12):1365 71, Estes J.D., Harris L.D., Klatt N.R., et al. Damaged intestinal epithelial integrity linked to microbial translocation in pathogenic simian immunodeficiency virus infections. PLoS Pathog. 2010;6:e1001052.

${ }^{29}$ Kapembwa MS, Fleming SC, Sewankambo N, et al. Altered small-intestinal permeability associated with diarrhoea in human-immunodeficiency-virus-infected Caucasian and African subjects. Clin Sci (Lond) 1991;81:327-334, Bjarnason I, Sharpstone DR, Francis N, et al. Intestinal inflammation, ileal structure and function in HIV. AIDS. 1996;10:1385-1391, Sharpstone D, Neild P, Crane R, et al. Small intestinal transit, absorption, and permeability in patients with AIDS with and without diarrhoea. Gut. 1999;45:70-76.

${ }^{30}$ Stein TP, Koerner B, Schluter MD, et al. Weight loss, the gut and the inflammatory response in aids patients. Cytokine. 1997;9:143-147, Anselmi A, Vendrame D, Rampon $\mathrm{O}$, Giaquinto C, Zanchetta M, De Rossi A. Immune reconstitution in human immunodeficiency virus type 1-infected children with different virological responses to anti-retroviral therapy. Clin Exp Immunol. 2007;150:442-450, Cecchinato V, Trindale C, Laurence A, et al. Altered balance between Th17 and Th1 cells at mucosal sites predicts AIDS progression in simian immunodeficienty virus-infected macaques. Mucosal Immunol. 2008;1:279-288, Balagopal A, Philp FH, Astemborski J, et al. Human immunodeficiency virus-related microbial translocation and progression of hepatitis C. Gastroenterology. 2008;135:226-233.

${ }^{31}$ McGowan I, Elliott J, Fuerst M, et al. Increased HIV-1 Mucosal Replication Is Associated With Generalized Mucosal Cytokine Activation. J Acquir Immune Defic Syndr. 2004;37:1228-1236, Clayton F, Reka S, Cronin WJ, et al. Rectal mucosal pathology varies with human immunodeficiency virus antigen content and disease stage. Gastroenterology. 1992;103:919-933, Kotler DP, Reka S, Clayton F. Intestinal mucosal inflammation associated with human immunodeficiency virus infection. Dig Dis Sci. 1993;38:1119-1127.

${ }^{32}$ Jiang W, Lederman MM, Hunt P, Sieg SF, Haley K, et al. Plasma levels of bacterial DNA correlate with immune activation and the magnitude of immune restoration in persons with antiretroviral-treated HIV infection. J Infect Dis. 2009;199:1177-1185, Brenchley JM Price DA, Schacker TW, et al. Microbial translocation is a cause of systemic immune activation in chronic HIV infection. Nat Med. 2006 Dec; 12(12):1365-71.

${ }^{33}$ Giorgi JV, Hultin LE, McKeating JA, et al. Shorter survival in advanced human immunodeficiency virus type 1 infection is more closely associated with T lymphocyte activation than with plasma virus burden or virus chemokine coreceptor usage. J Infect Dis. 1999;179:859-870. 
Children infected with HIV present with neurodevelopmental sequelae that include impairments in cognition, behaviours that include irritability, anxiety, and perseverative behaviours, and socialisation, language, and non-verbal communication deficits, all which perfectly mirror those of autism. ${ }^{34}$ Physiological abnormalities shared by both autism and individuals with HIV infection include abnormal immune reactions to gliadin and casein, intestinal permeability and malabsorption of nutrients, dysregulated production of digestive enzymes (impaired pancreatic function) and inability to digest complex carbohydrates, lactose and sugar intolerance, inability to absorb fats and protein, gastrointestinal pathogen overload (secondary intestinal viruses and bacterial imbalances), abnormal immune reactivity to Candida, impaired fine and gross motor skills, impaired sensory processing, mitochondrial dysfunction, cellular calcium overload, oxidative stress and glutathione depletion, microglial activation and inflammation, encephalopathy, glutamate and quinolinic acid excitotoxicity, and impaired methylation..$^{35}$ As seen in autism, children with HIV sometimes develop normally and regress between 1.5 to 2 years of age, and regression is linked to increased retroviral load. Moreover, severity of autistic symptoms in HIV positive children is correlated with levels of retroviral load/replication and level of $\mathrm{CD} 4^{+}$ T-cell depletion. ${ }^{36}$

Since autism is believed to be a psychiatric disorder and not a complex viral/complex neuroimmune disorder and properly classified in Chapter III of the WHO's International Classification of Diseases as "D89.89 Other specified disorders involving the immune mechanism, not elsewhere classified", there is no consensus regarding etiology or pathology of the disease and parents have been forced to scour the globe to ease the suffering for their children. Regardless, research and treatment of HIV has shown us that many treatments currently used for autism have proven or suspected antiretroviral effects that likely contributes to their success:

- Chelation of heavy metals inhibits HIV virus integration into human DNA and reduces viral load. ${ }^{37}$

- Tetracycline antibiotics inhibit HIV in a similar manner as chelation agents. $^{38}$

- Glutathione and agents that increase glutathione inhibit HIV. ${ }^{39}$

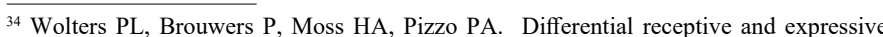
language functioning of children with symptomatic HIV disease and relation to CT scan brain abnormalities. Pediatrics. 1995 Jan;95(1):112-9, Moss HA, Brouwers P, Wolters PL, et al. The development of a Q-sort behavioral rating procedure for pediatric HIV patients. J Pediatr Psychol. 1994 Feb;19(1):27-46.

${ }^{35} \mathrm{http}: / /$ www.autismcalciumchannelopathy.com/HIV_and_Autism.html

${ }^{36}$ Yonk LJ et al. CD4+ helper T cell depression in autism. Immunol Lett. 1990 Sep;25(4):341-5.

${ }^{37}$ Grieb G. Alpha-lipoic acid inhibits HIV replication. Med Monatsschr Pharm. 1992 Aug;15(8):243-4, Disintegration of retroviruses by chelating agents - V. Wunderlich1 and G. Sydow1(1) April 1982. Central Institute for Cancer Research, Robert-Rössle-Institute, Academy of Sciences of the German Democratic Republic, Berlin, German Democratic Republic

${ }^{38}$ Neamati $\mathrm{N}$ et al. Potent inhibitors of human immunodeficiency virus type 1 integrase: identification of a novel four-point pharmacophore and tetracyclines as novel inhibitors. Mol Pharmacol. 1997 Dec;52(6):1041-55.

${ }^{39}$ Demirhan Ilhan et al. Inhibition of Tat-mediated HIV-1-LTR transactivation and virus replication by sulfhydryl compounds with chelating properties. Anticancer Res. 2000 JulAug;20(4):2513-7
}

- Antiviral agents have been shown to reduce HIV viral load.40

- Hyperbaric oxygen has been shown to inhibit HIV and reduce viral load. $^{41}$

- Pancreative enzymes may be beneficial in reducing viral load. ${ }^{42}$

- Methylation agents directly inhibit HIV activity and maintain its latency. ${ }^{43}$

Since the aforementioned treatments are effective in ameliorating the symptoms of autism in HIV infected children, then it stands to reason that the symptoms of autism are caused by immunological factors related to an underlying disease process, probably of viral origin, that is treatable and surmountable. It is also clear that HIV and autism share the same pathological features and, in all likelihood, the same etiology. More importantly, a single or a combination of antiretroviral treatments can diminish or completely eradicate the symptoms of autism in HIV infected children, sometimes with total remission of autistic symptoms.

Gastrointestinal disease is a hallmark symptom of HIV, but its manifestation was considered to be a consequence of the immune destruction that characterizes HIV rather than being fundamental to its pathogenesis. Fortunately for those afflicted, it soon became clear that gut immunity is central to the pathogenesis of HIV and the development of AIDS, since most of the critical events such as transmission, viral amplification, and $\mathrm{CD} 4^{+} \mathrm{T}$-cell destruction, occur in the gastrointestinal tract. $\mathrm{CD} 4^{+} \mathrm{T}$-cell development strictly depended on the resident microbiota, ${ }^{44}$ and in autism $\mathrm{CD} 4^{+} \mathrm{T}$-cell proliferation is also impaired. ${ }^{45}$ Ultimately though, as in autism, it is the chronic, persistent, dysfunctional inflammatory response by the immune system that leads to the development of AIDS.

Aberrant immune function in autism is now widely accepted but still many children and adults today are suffering from a condition that we are mistakenly calling autism and no effective medical treatments have become standard of care, despite the dramatically increasing

\footnotetext{
${ }^{40}$ Martelius T. Antiviral and immunomodulatory effects of desferrioxamine in cytomegalovirus-infected rat liver allografts with rejection. Transplantation. 1999 Dec 15;68(11):1753 61, McMahon MA, et al. The antiherpetic drug acyclovir inhibits HIV replication and selects the V75I reverse transcriptase multidrug resistance mutation. J Biol Chem. 2008 Nov 14;283(46):31289-93. Epub 2008 Sep 24, Lisco A et al. Acyclovir is activated into a HIV-1 reverse transcriptase inhibitor in herpesvirus-infected human tissues. Cell Host Microbe. 2008 Sep 11;4(3):260-70.

${ }^{41}$ Reillo MR et al. HIV antiviral effects of hyperbaric oxygen therapy. J Assoc Nurses AIDS Care. 1996 Jan-Feb;7(1):43-5.
}

${ }^{42}$ Lange $\mathrm{M}$ et al. Effect of enzyme therapy on HIV-RNA and CD4 counts in HIV seropositive subjects with CD4 count 200 to 500. Int Conf AIDS. 1996 Jul 7-12; 11: 91 (abstract no. We.B.3198). t. Luke's-Roosevelt Hospital, New York, NY, USA.

${ }^{43}$ Yedavalli VR, Jeang KT. Methylation: a regulator of HIV-1 replication? Retrovirology. $2007 \mathrm{Feb} 2 ; 4: 9$, Hofmann A et al. Epigenetic regulation of lentiviral transgene vectors in a large animal model. Mol Ther. 2006 Jan;13(1):59-66. Epub 2005 Sep 2, Tanaka J et al. Latent HIV-1 reactivation in transgenic mice requires cell cycle -dependent demethylation of CREB/ATF sites in the LTR. AIDS. 2003 Jan 24;17(2):167-75, Goggins Mum et al Methylation of cortical brain proteins from patients with HIV infection. Acta Neurol Scand. 1999 Nov;100(5):326-31, Mikovits JA et al. Infection with human immunodeficiency virus type 1 upregulates DNA methyltransferase, resulting in de novo methylation of the gamma interferon (IFN-gamma) promoter and subsequent downregulation of IFN-gamma production. Mol Cell Biol. 1998 Sep;18(9):5166-77.

${ }^{44}$ Garidou L, Pomié C, Klopp P, et al. The Gut Microbiota Regulates Intestinal CD4 T Cells Expressing ROR $\gamma \mathrm{t}$ and Controls Metabolic Disease. Cell Metab. 2015 Jul 7;22(1):100-12. doi: 10.1016/j.cmet.2015.06.001.

${ }^{45}$ Bilate AM, Bousbaine D, Mesin L, et al. Tissue-specific emergence of regulatory and intraepithelial T cells from a clonal T cell precursor. Sci Immunol. 2016 Aug 26;1(2):eaaf7471. doi: 10.1126/sciimmunol.aaf7471. Epub 2016 Aug 26. 
prevalence. A role for immunological involvement in autism has long been considered, as parallel evidence of immune abnormalities began to emerge in the context of a neuroimmune hypothesis. ${ }^{46}$ Several immunologic risk factors that have been described include maternal infection and inflammation during pregnancy, as discussed previously, heavy loading of autoimmune and immune related disorders in many families of children with autism, ${ }^{47}$ associations with immune-related genes, ${ }^{48}$ and altered immune responses in children with autism. ${ }^{49}$ Moreover, autoimmune and immune related disorders are known to share sharply increasing prevalence rates over the last decades, and Chen et al. found that children born to mothers with autoimmune disease were $34 \%$ more likely to develop autism. ${ }^{50}$

The immune system influences the central nervous system primarily through brain and immune signalling molecules (hormones, neurotransmitters, neuropeptides, cytokines) that facilitate mutual neuroimmune communication through the neuroendocrine pathway, the hypothalamic-pituitary-adrenal axis, and through the lymphoid organs of the lymphatic system. Failure to supply sufficient enteral nutrients and providing agents that suppress probiotic gut flora while decreasing protection against harmful pathogens, results in an increased risk of intestinal permeability, microbial translocation, and an overactive or underactive immune response, an immune failure to differentiate between self and non-self, or a complete breakdown of immune function. The result is chronic systemic inflammation, and

\footnotetext{
${ }^{46}$ Korvatska E, Van de Water J, Anders TF, Gershwin ME. Genetic and immunologic considerations in autism. Neurobiol Dis. 2002 Mar;9(2):107-25

${ }^{47}$ Keil A, Daniels JL, Forssen U, et al. Parental autoimmune diseases associated with autism spectrum disorders in offspring. Epidemiology. 2010 Nov; 21(6):805-8, Comi AM, Zimmerman AW, Frye VH, Law PA, Peeden JN. Familial Clustering of Autoimmune Disorders and Evaluation of Medical Risk Factors in Autism. Journal of Child Neurology. 1999;14:388-394, Atladóttir HO, Pedersen MG, Thorsen P, et al. Association of family history of autoimmune diseases and autism spectrum disorders. Pediatrics. 2009;124:687694, Vinet É, Pineau CA, Clarke AE, Scott S, Fombonne É, Joseph L, et al. Increased Risk of Autism Spectrum Disorders in Children Born to Women With Systemic Lupus Erythematosus: Results From a Large Population-Based Cohort. Arthritis \& rheumatology (Hoboken, NJ). 2015;67:3201-3208, Croen LA, Grether JK, Yoshida CK, Odouli $\mathrm{R}$, Van de Water J. Maternal autoimmune diseases, asthma and allergies, and childhood autism spectrum disorders: a case-control study. Arch Pediatr Adolesc Med. 2005 Feb; 159(2):151-7, Wu S, Ding Y, Wu F, et al. Family history of autoimmune diseases is associated with an increased risk of autism in children: A systematic review and meta-analysis. Neuroscience and biobehavioral reviews. 2015;55:322-332.
}

${ }^{48}$ Torres AR, Westover JB, Gibbons C, Johnson RC, Ward DC. Activating killer-cell immunoglobulin-like receptors (KIR) and their cognate HLA ligands are significantly increased in autism. Brain, behavior, and immunity. 2012;26:1122-1127, Warren RP, Singh $\mathrm{VK}$, Cole $\mathrm{P}$, et al. Increased frequency of the null allele at the complement $\mathrm{C} 4 \mathrm{~b}$ locus in autism. Clinical \& Experimental Immunology. 1991;83:438-440, Mostafa GA, Shehab AA. The link of C4B null allele to autism and to a family history of autoimmunity in Egyptian autistic children. Journal of Neuroimmunology. 2010;223:115-119, Jung JY, Kohane IS, Wall DP. Identification of autoimmune gene signatures in autism. Translational psychiatry. 2011;1:e63-e63, Warren RP, Odell JD, Warren WL, et al. Strong association of the third hypervariable region of HLA-DR $\beta 1$ with autism. Journal of Neuroimmunology. 1996;67:97-102, Torres AR, Sweeten TL, Cutler A, Bedke BJ, Fillmore M, Stubbs EG, et al. The association and linkage of the HLA-A2 class I allele with autism. Human immunology. 2006;67:346-351, Campbell DB, Li C, Sutcliffe JS, Persico AM, Levitt P. Genetic evidence implicating multiple genes in the MET receptor tyrosine kinase pathway in autism spectrum disorder. Autism Research. 2008;1:159-168, Thanseem I, Nakamura K, Miyach T, Toyota T, Yamada S, Tsujii M, et al. Further evidence for the role of MET in autism susceptibility. Neuroscience Research. 2010;68:137-141.

${ }^{49}$ Ashwood P, Van de Water J. Is autism an autoimmune disease? Autoimmunity reviews. 2004;3:557-562, Mead J, Ashwood P. Evidence supporting an altered immune response in ASD. Immunol Lett. 2015 Jan;163(1):49-55. doi: 10.1016/j.imlet.2014.11.006. Epub 2014 Nov 20.

${ }^{50}$ Chen S-W, Zhong X-S, Jiang L-N, et al. Maternal autoimmune diseases and the risk of autism spectrum disorders in offspring: A systematic review and meta-analysis. Behavioural brain research. 2016;296:61-69. possibly even death since the same mechanisms are at work in immune dysfunction as they are in Sudden Infant Death Syndrome (SIDS). SIDS occurs when you have an infant who is at a critical stage of development, has an underlying immune related biological vulnerability, ${ }^{51}$ has an uncolonized gut microbiome that is unable to control inflammation and is comprised of an increased number of pathogenic microbes, ${ }^{52}$ who is then exposed to external triggers. ${ }^{53}$ SIDS babies also often have a history of viral illness preceding death ${ }^{54}$ and elevated pro-inflammatory cytokines $^{55}$ that likely influence the integrity of the epithelial barrier leading to increased microbial translocation and a resulting chronic inflammatory response. As in autism and ADHD, SIDS affects more males than females.

The developing microbiome plays a key role in the formation of the neonatal immune system, and dysregulation of the microbiome can significantly impact systemic immunity. ${ }^{56}$ The microbiome regulates inflammation and also exerts numerous effects on the intestinal neuroimmune system. ${ }^{57}$ The neuroimmune system is a system of structures and processes involving the signalling between the nervous

\footnotetext{
$\overline{{ }^{51} \text { Highet AR, Berry AM}}$, Goldwater PN. Novel hypothesis for unexplained sudden unexpected death in infancy (SUDI). Arch Dis Child. 2009 Nov: 94(11):841-3, Fard D, Läer $\mathrm{K}$, Rothämel T, et al. Candidate gene variants of the immune system and sudden infant death syndrome. Int J Legal Med. 2016 Jul;130(4):1025-1033. doi: 10.1007/s00414-0161347-y. Epub 2016 Mar 14.
}

${ }^{52}$ Highet AR, Berry AM, Bettelheim KA, Goldwater PN. Gut microbiome in sudden infant death syndrome (SIDS) differs from that in healthy comparison babies and offers an explanation for the risk factor of prone position. Int J Med Microbiol. 2014 Jul; 304(56):735-41, Lindsay JA, Mach A, Wilkinson MA, Martin LM, Wallace FM, Keller AM, et al. Clostridium perfringens type-A cytotoxic-enterotoxin(s) as triggers for death in the sudden-infant-death-syndrome development of a toxico-infection hypothesis. Curr Microbiol (1993) 27:51-9.10.1007/BF01576834, Murrell WG, Stewart BJ, O'Neill C, Siarakas S, Kariks $S$. Enterotoxigenic bacteria in the sudden infant death syndrome. J Med Microbiol. 1993 Aug; 39(2):114-27, Malam JE, Carrick GF, Telford DR, Morris JA. Staphylococcal toxins and sudden infant death syndrome. J Clin Pathol (1992) 45:716-21.10.1136/ jcp.45.8.716, Zorgani A, Essery SD, Madani OA, et al. Detection of pyrogenic toxins of Staphylococcus aureus in sudden infant death syndrome. FEMS Immunol Med Microbiol (1999) 25(1-2):103-8.10.1111/j.1574-695X.1999.tb01332.x, Blackwell CC, Gordon AE James VS, et al. The role of bacterial toxins in sudden infant death syndrome (SIDS). In J Med Microbiol (2002) 291(6-7):561-70.10.1078/1438-4221-00168, Highet AR, Goldwater PN. Staphylococcal enterotoxin genes are common in Staphylococcus aureus intestinal flora in sudden infant death syndrome (SIDS) and live comparison infants. FEMS Immunol Med Microbiol (2009) 57(2):151-5.10.1111/j.1574-695X.2009.00592.x, Bettelheim KA, Goldwater PN, Dwyer BW, Bourne AJ, Smith DL. Toxigenic Escherichia coli associated with sudden infant death syndrome. Scand J Infect Dis (1990) 22:46776.10.3109/00365549009027079, Bettiol SS, Radcliff FJ, Hunt ALC, Goldsmid JM. Bacterial flora of Tasmanian SIDS infants with special reference to pathogenic strains of Escherichia coli. Epidemiol Infect (1994) 112:275-84.10.1017/S095026880005768X.

${ }^{53}$ Jonathan C. Makielski. SIDS: genetic and environmental influences may cause arrhythmia in this silent killer. J Clin Invest. 2006 Feb 1; 116(2): 297-299. doi: 10.1172/ JC127689, Blood-Siegfried J. The Role of Infection and Inflammation in Sudden Infan death Syndrome. Immunopharmacology and immunotoxicology. 2009;31(4):516-523. doi:10.3109/08923970902814137.

${ }^{54}$ Hoffman HJ, Damus K, Hillman L, Krongrad E. Risk factors for SIDS. Results of the National Institute of Child Health and Human Development SIDS Cooperative Epidemiological Study. Ann N Y Acad Sci. 1988; 533():13-30.

${ }^{55}$ Vege A, Rognum TO, Scott H, Aasen AO, Saugstad OD. SIDS cases have increased levels of interleukin-6 in cerebrospinal fluid. Acta Paediatr. 1995 Feb; 84(2):193-6.

${ }^{56}$ Gomez de Agüero, M., Ganal-Vonarburg, S. C., Fuhrer, et al. The maternal micro- biota drives early postnatal innate immune development. Science. (2016). 351, 1296-1302.

${ }^{57}$ Bercik P, Collins SM, Verdu EF. Microbes and the gut-brain axis. Neurogastroenterol Motil. 2012 May; 24(5):405-13, Grenham S, Clarke G, Cryan JF, Dinan TG. Brain-gutmicrobe communication in health and disease. Front Physiol. 2011; 20:94, Maranduba CM da C, De Castro SBR, de Souza GT, et al. Intestinal Microbiota as Modulators of the Immune System and Neuroimmune System: Impact on the Host Health and Homeostasis. Journal of Immunology Research. 2015;2015:931574. doi:10.1155/2015/931574 
system and immune system. It is comprised primarily of glial cells ${ }^{58}$ and protects neurons against disease by maintaining permeable barriers, such as the $\mathrm{BBB}$, mediating neuroinflammation, promoting wound healing in damaged neurons, and summoning host defenses against pathogens. ${ }^{59}$ The glial cells of the ENS, the enteric glia, lie beneath the intestinal epithelial cells and are also distributed throughout the gut wall, including the area of the mucosa. In addition to their role in supporting neural circuits, the glia plays a role in strengthening the intestinal epithelial barrier, ${ }^{60}$ preventing gut inflammation, ${ }^{61}$ and in supporting muscular digestive processes. ${ }^{62}$

There are four types of glial cells of the CNS that maintain homeostasis, form myelin, and surround neurons to insulate them and hold them in place: 1) astrocytes, which attach to blood vessels and provide nutrients and oxygen to neurons, 2) oligodendrocytes, which form myelin in the brain and spinal cord, 3) ependymal cells, which are involved in the production of cerebrospinal fluid and also serve as a reservoir for neuro-regeneration, and 4) microglia, which protect the neurons from environmental insults.

CNS inflammation is primarily driven by microglial cells which secrete proinflammatory cytokines. ${ }^{63}$ In a healthy brain, the microglia constantly survey all aspects of their environment and facilitate the coordinated responses between the immune system and the brain. The microglia constitute about $10 \%$ of the total cells in the adult $\mathrm{CNS}^{64}$ and act as a first line of active immune defense in the brain and spinal cord. In response to injury, inflammation, neurodegeneration, infection, and brain tumors, the microglia multiply and enter an activated state to engulf and eliminate harmful debris - a process known as priming. ${ }^{65}$ Microglia are the most active cytokine producing cells in the brain and when primed in response to immunological stimuli they release proinflammatory cytokines, such as nitric oxide and neurotrophic factors. ${ }^{66}$

\begin{abstract}
${ }^{58}$ Beardsley PM, Hauser KF. Glial modulators as potential treatments of psychostimulant abuse. Adv. Pharmacol. 2014. 69: 1-69. doi:10.1016/B978-0-12-420118-7.000019, Veiga-Fernandes H, Mucida D. Neuro-immune interactions at barrier surfaces. Cell. 2016;165(4):801-811. doi:10.1016/j.cell.2016.04.041, Gimsa U, Mitchison NA, Brunner-Weinzierl MC. Immune privilege as an intrinsic CNS property: astrocytes protec the CNS against T-cell-mediated neuroinflammation. Mediators Inflamm. 2013: 320519.
\end{abstract} doi: $10.1155 / 2013 / 320519$.

${ }^{59}$ Rogers TJ. The molecular basis for neuroimmune receptor signaling. J Neuroimmune Pharmacol. 2012. 7 (4): 722-4. doi:10.1007/s11481-012-9398-4. PMC 4011130 Freely accessible. PMID 22935971, Gimsa U, Mitchison NA, Brunner-Weinzierl MC. Immune privilege as an intrinsic CNS property: astrocytes protect the CNS against T-cell-mediated neuroinflammation. Mediators Inflamm. 2013: 320519. doi:10.1155/2013/320519.

${ }^{60}$ Neunlist M, Van Landeghem L, Mahe MM, et al. The digestive neuronal-glial-epithelial unit: a new actor in gut health and disease. Nat Rev Gastroenterol Hepatol 2013; 10:90-100; PMID:23165236; http://dx.doi.org/10.1038/nrgastro.2012.221

${ }^{61}$ Bush TG, Savidge TC, Freeman TC, et al. Fulminant jejuno-ileitis following ablation of enteric glia in adult transgenic mice. Cell 1998; 93:189-201; PMID:9568712; http://dx.doi. org/10.1016/S0092-8674(00)81571-8

${ }^{62}$ Bassotti G, Villanacci V, Antonelli E, Morelli A, Salerni B. "Enteric glial cells: new players in gastrointestinal motility?". Laboratory Investigation. (July 2007) 87 (7): 628-32

${ }^{63}$ H. Kettenmann, U.K. Hanisch, M. Noda, A. Verkhratsky. Physiology of microglia. Physiol. Rev., 91 (2) (2011), pp. 461-553, R.M. Ransohoff, D. Schafer, A. Vincent, N.E. Blachere, A. Bar-Or. Neuroinflammation: ways in which the immune system affects the brain. (2015). Neurotherapeutics, R. Yamasaki, H. Lu, O. Butovsky, et al. Differential roles of microglia and monocytes in the inflamed central nervous system.

${ }^{64}$ Aguzzi A, Barres BA, Bennett ML. Microglia: Scapegoat, Saboteur, or Something Else? Science (New York, NY). 2013;339(6116):156-161. doi:10.1126/science.1227901.

${ }^{65}$ Perry V. H., Holmes C. Microglial priming in neurodegenerative disease. Nat. Rev. Neurol. (2014). 10, 217-224. 10.1038/nrneurol.2014.38

${ }^{66}$ Kato T. A., Watabe M., Kanba S. Neuron-glia interaction as a possible glue to translate the mind-brain gap: a novel multi-dimensional approach toward psychology and psych-
The magnitude of microglial activation following an immune insult is dependent on the type and potency of the stimulus, and the exposure to prior and existing stimuli that may result in a state of persistently primed microglia and an exaggerated inflammatory response. This microglial hyper-activation following an immune challenge results in amplified and prolonged neuroinflammation, sickness behaviour, depressive-like behaviour, and cognitive deficits. ${ }^{67}$ Chronically activated microglia also release excessive amounts of superoxide free radicals and extracellular reactive oxygen species that are highly reactive and can damage proteins, lipids, and nucleotides, resulting in cell dysfunction and death. ${ }^{68}$ The reason for excessive and prolonged activation of the microglia is not well understood but an unabating barrage of insults would constitute a situation whereby primed microglia may be unable to return to their resting state. Additionally, since neural tissues have restricted cell renewal and regeneration capacity, the CNS is extremely vulnerable to uncontrolled inflammatory processes. Microglial activation has been described in the literature as chronic microglial encephalomyelitis, viral encephalitis, autoimmune encephalitis and microgliosis. A large body of evidence now shows that dysregulated microglial functioning plays a critical role in the pathophysiology of autism. ${ }^{69}$

The discovery in 2005 by a team of researchers led by neurologist Carlos Pardo at Johns Hopkins, which demonstrated that microglial cells were activated in individuals with autism, ${ }^{70}$ precipitated further advances in understanding the role of the microglia in normal development of the CNS, in addition to their contribution to CNS immunity. There is now increasing evidence that supports the notion that chronic and prolonged activation of the microglia in autism can compromise neuronal functioning by inducing a cascade of further inflammatory cytokines and oxidative stress, resulting in impaired neuronal communication and underconnectivity. ${ }^{71}$ Underconnectivity

iatry. Front. Psychiatry. (2013). 4:139. 10.3389/fpsyt.2013.00139, Monji A., Kato T A., Mizoguchi Y., et al. Neuroinflammation in schizophrenia especially focused on the role of microglia. Prog. Neuropsychopharmacol. Biol. Psychiatry. (2013). 42, 115-121. 10.1016/j.pnpbp.2011.12.002, Monji A., Maezawa I., Mizoguchi Y., Kato T. A., Jin L.-W. "Neurodevelopmental and neuropsychiatric disorders," in Microglia in Health and Disease. Eds Tremblay M.-E., Sierra A., editors. New York, NY: Springer Science + Business Media. (2014). 345-372, Mizoguchi Y., Kato T. A., Horikawa H., Monji A. Microglial intracellular $\mathrm{Ca}^{2+}$ signaling as a target of antipsychotic actions for the treatment of schizophrenia. Front. Cell. Neurosci. (2014a) 8:370. 10.3389/fncel.2014.00370, Smith A. M., Dragunow M. The human side of microglia. Trends Neurosci. (2014). 37, 125-135. 10.1016/j.tins.2013.12.001

${ }^{67}$ D. M. Norden and J. P. Godbout. Microglia of the aged brain: primed to be activated and resistant to regulation (2013) Neuropathology and Applied Neurobiology 39, 19-34 $39: 1,19-34$

${ }^{68}$ Thomas, Madhavi (Ed.). 2014. Inflammation in Parkinson's Disease. Scientific and Clinical Aspects. Springer International Publishing Switzerland.

${ }^{69}$ Kern JK, Geier DA, Sykes LK, Geier MR. Relevance of Neuroinflammation and Encephalitis in Autism.

Frontiers in Cellular Neuroscience. 2015;9:519. doi:10.3389/fncel.2015.00519.

${ }^{70}$ Vargas DL1, Nascimbene C, Krishnan C, Zimmerman AW, Pardo CA. Neuroglial activation and neuroinflammation in the brain of patients with autism. Ann Neurol. 2005 Jan;57(1):67-81.

${ }^{71}$ Balschun D, Wetzel W, Del Rey A, et al. Interleukin-6: a cytokine to forget. FASEB $J$. 2004;18:1788-1790, Lynch MA. Interleukin-1 beta exerts a myriad of effects in the brain and in particular in the hippocampus: analysis of some of these actions. Vitam Horm 2002;64:185-219, Pickering M, O'Connor JJ. Pro-inflammatory cytokines and their effects in the dentate gyrus. Prog Brain Res. 2007;163:339-354, Salter M. W., Beggs S. Sublime microglia: expanding roles for the guardians of the CNS. Cell. (2014). 158, 15-24 10.1016/j.cell.2014.06.008, Ziats M. N., Edmonson C., Rennert O. M. The autistic brain in the context of normal neurodevelopment. Front. Neuroanat. (2015). 9:115. 10.3389, fnana.2015.00115, Macht V. A. Neuro-immune interactions across development: a look at glutamate in the prefrontal cortex. Neurosci. Biobehav. (2016). Rev. 71, 267-280 10.1016/j.neubiorev.2016.08.039. 
has long been recognized in autism and the severity of autistic symptoms correlates with degree of underconnectivity. ${ }^{72}$ The host microbiome regulates microglia maturation and function, ${ }^{73}$ and microglial activation in response to pathogens, ${ }^{74}$ environmental toxins, ${ }^{75}$ and a nutrient-free diet, ${ }^{76}$ is also now implicated in the pathophysiology of SIDS, ${ }^{77}$ epilepsy, ${ }^{78}$ cancer, ${ }^{79}$ HIV/AIDS, ${ }^{80}$ substance use disorders, ${ }^{81}$ Fetal Alcohol Spectrum Disorders, ${ }^{82}$ neurodegenerative disorders ${ }^{83}$

${ }^{72}$ Barttfeld P, Wicker B, Cukier S, Navarta S, Lew S, Sigman M. A big-world network in ASD: dynamical connectivity analysis reflects a deficit in long-range connections and an excess of short-range connections. Neuropsychologia. 2011 Jan; 49(2):254-63.

${ }^{73}$ Erny D, de Angelis ALH, Jaitin D, et al. Host microbiota constantly control maturation and function of microglia in the CNS. Nature neuroscience. 2015;18(7):965-977. doi:10.1038/nn.4030, Erny D, Hrabě de Angelis AL, Prinz M. Communicating systems in the body: how microbiota and microglia cooperate. Immunology. 2017;150(1):7-15. doi:10.1111/imm.12645.

${ }^{74}$ Brissette CA, Houdek HM, Floden AM, Rosenberger TA. Acetate supplementation reduces microglia activation and brain interleukin- $1 \beta$ levels in a rat model of Lyme neuroborreliosis. Journal of Neuroinflammation. 2012;9:249. doi:10.1186/1742-2094-9-249, Sadasivan S, Zanin M, O'Brien K, Schultz-Cherry S, Smeyne RJ (2015) Induction of Microglia Activation after Infection with the Non-Neurotropic A/CA/04/2009 H1N1 Influenza Virus. PLOS ONE 10(4): e0124047. https://doi.org/10.1371/journal.pone.0124047

${ }^{75}$ Hossain MM, Liu J, Richardson JR. Pyrethroid Insecticides Directly Activate Microglia Through Interaction With Voltage-Gated Sodium Channels. Toxicol Sci. 2017 Jan;155(1):112-123. doi: 10.1093/toxsci/kfw187. Epub 2016 Sep 21, Liu B, Gao H-M, Hong J-S. Parkinson's disease and exposure to infectious agents and pesticides and the occurrence of brain injuries: role of neuroinflammation. Environmental Health Perspectives. 2003;111(8):1065-1073, Wang X, Cochran TA, Hutchinson MR, et al. "Drug Addiction," in Microglia in Health and Disease. Eds Tremblay M.-E., Sierra A., editors. New York, NY: Springer Science + Business Media. (2014). 345-372, Kumawat KL, Kaushik DK, Goswami P, Basu A. Acute exposure to lead acetate activates microglia and induces subsequent bystander neuronal death via caspase-3 activation. Neurotoxicology. 2014 Mar;41:143-53. doi: 10.1016/j.neuro.2014.02.002. Epub 2014 Feb 14, Ni M, Li X, Yin $\mathrm{Z}$, et al. Methylmercury Induces Acute Oxidative Stress, Altering Nrf2 Protein Level in Primary Microglial Cells. Toxicological Sciences. 2010;116(2):590-603. doi:10.1093/toxsci/kfq126, Kern JK, Geier DA, Audhya T, et al. Evidence of parallels between mercury intoxication and the brain pathology in autism.

${ }^{76}$ Maysinger D, Zhang I. Nutritional and Nanotechnological Modulators of Microglia. Frontiers in Immunology. 2016;7:270. doi:10.3389/fimmu.2016.00270, Derrick F. MacFabe, Donald P. Cain, Karina Rodriguez-Capote, et al. Neurobiological effects of intraventricular propionic acid in rats: Possible role of short chain fatty acids on the pathogenesis and characteristics of autism spectrum disorders. Behavioural Brain Research. Volume 176, Issue 1, 2007, Pages 149-169. ISSN 0166-4328.

${ }_{77}$ MacFarlane PM, Mayer CA, Litvin DG. Microglia modulate brainstem serotonergic expression following neonatal sustained hypoxia exposure: implications for sudden infant death syndrome. The Journal of Physiology. 2016;594(11):3079-3094. doi:10.1113/ JP271845, Biondo, B., Magagnin, S., Bruni, B. et al. Glial and neuronal alterations in the nucleus tractus solitarii of sudden infant death syndrome victimsActa Neuropathol (2004) 108: 309. https://doi.org/10.1007/s00401-004-0895-2

${ }^{78}$ Devinsky O, Vezzani A, Najjar S, De Lanerolle NC, Rogawski MA. Glia and epilepsy: excitability and inflammation. Trends Neurosci. 2013 Mar;36(3):174-84. doi: 10.1016/j. tins.2012.11.008. Epub 2013 Jan 5. Review.

${ }^{79} \mathrm{Wu}$ S-Y, Watabe $\mathrm{K}$. The roles of microglia/macrophages in tumor progression of brain cancer and metastatic disease. Frontiers in bioscience (Landmark edition). 2017;22:1805-1829.

${ }^{80}$ Walsh JG, Reinke SN, Mamik MK, et al. Rapid inflammasome activation in microglia contributes to brain disease in HIV/AIDS. Retrovirology. 2014;11:35. doi:10.1186/17424690-11-35.

${ }^{81}$ Marshall SA, McClain JA, Kelso ML, Hopkins DM, Pauly JR, Nixon K. Microglial activation is not equivalent to neuroinflammation in alcohol-induced neurodegeneration: the importance of microglia phenotype. Neurobiology of disease. 2013;54:239-251. doi:10.1016/j.nbd.2012.12.016, Miguel-Hidalgo JJ. The Role of Glial Cells in Drug Abuse. Current drug abuse reviews. 2009;2(1):76-82.

${ }^{82}$ Boschen, K., Ruggiero, M.J., Klintsova, A.Y., (2016) Neonatal binge alcohol exposure increases microglial activation in the developing rat hippocampus. Neuroscience 324: 355-366. DOI: 10.1016/j.neuroscience.2016.03.033, Munekazu Komada, Nao Hara, Satoko Kawachi, et al. Mechanisms underlying neuro-inflammation and neurodevelopmental toxicity in the mouse neocortex following prenatal exposure to ethanol. 10 July 2017. Scientific Reports. Volume 7, Article number: 4934 (2017).

${ }^{83}$ Edison P, Ahmed I, Fan Z, et al. Microglia, Amyloid, and Glucose Metabolism in Parkinson's Disease with and without Dementia. Neuropsychopharmacology. 2013;38(6):938- obesity, ${ }^{84}$ diabetes, ${ }^{85}$ autoimmune disorders and tic disorders, ${ }^{86}$ infectious disease, ${ }^{87}$ and psychiatric disorders. ${ }^{88}$ Underscoring the importance of supporting the immune system, Cao et al., report that prior activation of microglia during embryogenesis may drive lasting neuro-immune responses and lead to later life susceptibility to inflammation. ${ }^{89}$ Essentially, microglial activation, as a downstream effect of alterations in the microbiome, may be at the root of every chronic condition known to man.

Historically, the CNS was thought to be isolated from the immune system and therefore had little or no role in CNS neural networks and communication pathway, but recent findings in microglial activation have raised significant questions about long-held beliefs and led to a watershed discovery that profoundly changed the landscape of immunological research. In 2015, University of Virginia School of Medicine researchers Jonathan Kipnis and Antoine Louveau overturned decades of textbook teaching when they discovered a set of meningeal lymphatic vessels that directly connect the CNS to the immune system. This revelation fundamentally changes how we view brain-immune interactions. ${ }^{90}$ The brain was previously considered an immune-privileged organ devoid of lymphatic vasculature but this discovery demonstrates that pathogens and environmental toxins that have the potential to traverse the $\mathrm{BBB}$ now have a direct route to the brain. It is clear now that our immune systems do not control the microbes in our gut but rather the microbes are regulating our immune

949. doi:10.1038/npp.2012.255, Lih-Fen Lue, Douglas G. Walker, Joseph Rogers. Modeling microglial activation in Alzheimer's disease with human postmortem microglial cultures Neurobiology of Aging. Volume 22, Issue 6, 2001, Pages 945-956, ISSN 01974580. https://doi.org/10.1016/S0197-4580(01)00311-6.

${ }^{84}$ Joshua P. Thaler, Chun-Xia Yi, Ellen A. Schur, et al. Obesity is associated with hypothalamic injury in rodents and humans. J Clin Invest. 2012;122(1):153-162.

${ }^{85}$ Hwang IK, Choi JH, Nam SM, et al. Activation of microglia and induction of pro-inflammatory cytokines in the hippocampus of type 2 diabetic rats. Neurol Res. 2014 Sep;36(9):824-32. doi: 10.1179/1743132814Y.0000000330. Epub 2014 Feb 27.

${ }^{86}$ Tobias Goldmann and Marco Prinz, "Role of Microglia in CNS Autoimmunity," Clinical and Developmental Immunology, vol. 2013, Article ID 208093, 8 pages, 2013, Nicolini H, López Y, Genis-Mendoza AD, et al. Detection of anti-streptococcal, antienolase, and anti-neural antibodies in subjects with early-onset psychiatric disorders. Actas Esp Psiquiatr (2015) 43:35, Yaddanapudi K, Hornig M, Serge R, et al. Passive transfer of streptococcus-induced antibodies reproduces behavioral disturbances in a mouse model of pediatric autoimmune neuropsychiatric disorders associated with streptococcal infection. $\mathrm{Mol}$ Psychiatry (2010) 15:712. doi:10.1038/mp.2009.77, Frick L, Pittenger C. Microglial Dysregulation in OCD, Tourette Syndrome, and PANDAS. Journal of Immunology Research 2016;2016:8606057. doi:10.1155/2016/8606057.

${ }^{87}$ Mariani MM, Kielian T. Microglia in Infectious Diseases of the Central Nervous System. Journal of neuroimmune pharmacology : the official journal of the Society on NeuroImmune Pharmacology. 2009;4(4):448-461. doi:10.1007/s11481-009-9170-6.

${ }^{88}$ Takahashi Y, Yu Z, Sakai M, Tomita H. Linking Activation of Microglia and Peripheral Monocytic Cells to the Pathophysiology of Psychiatric Disorders. Frontiers in Cellular Neuroscience. 2016;10:144. doi:10.3389/fncel.2016.00144, Raz Yirmiya, Neta Rimmerman, Ronen Reshef. Depression as a Microglial Disease. NEUROIMMUNOLOGY. VOLUME 38, ISSUE 10, P637-658, OCTOBER 01, 2015, Wouter Beumer, Sinead M. Gibney, Roosmarijn C. Drexhage, et al. The immune theory of psychiatric diseases: a key role for activated microglia and circulating monocytes. Journal of Leukocyte Biology Vol.92, No.5 , pp:959-975, September, 2016, Tomoko Shigemori, Atsushi Sakai, Toru Takumi, et al. Altered Microglia in the Amygdala Are Involved in Anxiety-related Behaviors of a Copy Number Variation Mouse Model of Autism. Journal of Nippon Medical School. 2015 Volume 82 Issue 2 Pages 92-9, Steiner J, Walter M, Gos T, et al. Severe depression is associated with increased microglial quinolinic acid in subregions of the anterior cingulate gyrus: Evidence for an immune-modulated glutamatergic neurotransmission? Journal of Neuroinflammation. 2011;8:94. doi:10.1186/1742-2094-8-94.

${ }^{89}$ Cao Mingju, Cortes Marina, Moore Craig, et al. Fetal microglial phenotype in vitro carries memory of prior in vivo exposure to inflammation. Frontiers in Cellular Neuroscience. Vol. 9, 2015, P.294. DOI=10.3389/fncel.2015.00294

${ }^{90}$ Louveau A, Smirnov I, Keyes TJ, et al. Structural and functional features of central nervous system lymphatic vessels. Nature. 2015 Jun 1. doi: 10.1038/nature14432 PMID: 26030524 
systems, and most other body functions. The immune system, the heart of all body systems, is very active in the gut and microbes are among the most critical environmental factors which provide the specific signals involved in immune system development and maturation. ${ }^{91}$

The emerging research, albeit limited, is also now corroborating the overlapping and similar symptomology within various disorders. Rommelse et al. revealed that up to $80 \%$ of children with autism also meet the diagnostic criteria for $\mathrm{ADHD}^{92}$ and the relationship between borderline personality disorder, bipolar disorder, and ADHD was reviewed in 2014 and it was found that diagnostic overlap within the three disorders was $54 \% .^{93}$ More importantly, Nazeen et al. found that autism shares genes in innate immunity pathways that overlap with its comorbid conditions asthma, bacterial and viral infections, chronic kidney disease, cerebral palsy, dilated cardiomyopathy, ear infection, epilepsy, inflammatory bowel disease, muscular dystrophy, schizophrenia, and upper respiratory infection, ${ }^{94}$ and Dr. Martha Herbert's ground-breaking publication revealed that there is a genetic overlap between autism and cancer, metabolic, neurodegenerative, and heart diseases, further elucidating the shared biological underpinnings of major chronic inflammatory and environmentally influenced conditions. ${ }^{95}$

Today, the WHO recognizes chronic disease as the leading cause of disability and death in the world and reports that $24 \%$ of the disease burden and an estimated $23 \%$ of all premature deaths are attributable to environmental factors, ${ }^{96}$ yet environmental factors are consistently overlooked by psychiatric and medical practitioners as a cause of ill health. The shifting diagnostic criteria of the DSM to ensure that mental disorders remain diagnosable within the psychiatric realm, the evidence that microbiome alterations and microglial activation are detectable in almost every chronic condition, and the proof of overlapping symptomology of autism and multiple other inflammatory diseases tells us that we can no longer diagnose children and adults with mental illness while relying solely on behavioral criteria and ignoring evidenced biological underpinnings.

\section{Treatment}

Historically, treatment of autism has met with little success, with the exception of anecdotal cases of recovery that have essentially paved

${ }_{91}$ Izaskun García-Mantrana, Bibiana Bertua, Cecilia Martínez-Costa, Maria Carmen Collado. Perinatal nutrition: How to take care of the gut microbiota? Clinical Nutrition Experimental. Volume 6, April 2016, Pages 3-16, Hooper LV, Littman DR, Macpherson AJ. Interactions between the microbiota and the immune system. Science (New York, NY). 2012;336(6086):1268-1273. doi:10.1126/science.1223490

${ }^{92}$ Nanda N. J. Rommelse, Barbara Franke, Hilde M. Geurts, Catharina A. Hartman, Jan K. Buitelaar. Shared heritability of attention-deficit/hyperactivity disorder and autism spectrum disorder. European Child \& Adolescent Psychiatry. March 2010, Volume 19, Issue 3, pp 281-295

${ }^{93}$ Dominique Eich, Alex Gamma, Tina Malti, et al. Temperamental differences between bipolar disorder, borderline personality disorder, and attention deficit/hyperactivity disorder: Some implications for their diagnostic validity. Journal of Affective Disorders. 2014. Volume 169, Pages 101-104. ISSN 0165-0327 https://doi.org/10.1016/j.jad.2014.05.028

${ }^{94}$ Sumaiya Nazeen, Nathan P. Palmer, Bonnie Berger, Isaac S. Kohane. Integrative analysis of genetic data sets reveals a shared innate immune component in autism spectrum disorder and its co-morbidities. Genome Biology. 2016. 17:228.

${ }^{95}$ Wen Y, Alshikho MJ, Herbert MR. Pathway Network Analyses for Autism Reveal Multisystem Involvement, Major Overlaps with Other Diseases and Convergence upon MAPK and Calcium Signaling. (2016) PLOS ONE 11(4): e0153329. https://doi.org/10.1371/journal.pone. 0153329

${ }^{96}$ A. Prüss-Üstün and C. Corvalán. PREVENTING DISEASE THROUGH HEALTHY ENVIRONMENTS: Towards an estimate of the environmental burden of disease. ISBN 92 41593822 (NLM classification: WA 30.5) the way for the implementation of a successful treatment protocol. Despite over thirty years of research, a reliable marker for autism has not been identified, current pharmaceuticals fail to address the core symptoms and carry significant risks, dietary interventions have not been entirely effective, efforts to correct gut dysbiosis with supplements and probiotic therapy have imparted little benefit, and behavioral modification and structured education have shown to be somewhat advantageous in certain cases but overall insufficient and, in some cases, highly damaging. ${ }^{97}$ Dr. Goldberg's research, expertise and successful treatment of NIDS, however, has opened the door to an effective clinical protocol that is designed to restore/manipulate the microbiota while simultaneously reducing neuro-inflammation through the removal of environmental triggers and the use of pharmaceuticals such as antivirals, antibiotics, and antifungals, which target the agents that induce microglial activation. All this is then followed by intensive and sustained rehabilitation. The result of his treatment efforts effectively unburden an overwhelmed immune system and return the brain to a more functional state, as neuroinflammation is reduced, particularly in the temporal lobes, which reproducibly have proven to be hypoperfused, as evidenced by NeuroSPECT scans. ${ }^{98}$

Single photon emission computed tomography, or NeuroSPECT, reflects hypoperfusion and hyperperfusion in the brain and is currently the most objective piece of data that we have to clinically diagnose neuroimmune disorders. MRI and CT findings are often unremarkable, ${ }^{99}$ and if abnormalities are detected, the findings cannot be interpreted by most medical professionals. Perfused areas of the brain, as seen with NeuroSPECT, are a direct consequence of sustained and prolonged inflammation resulting from microglial activation, which commonly occurs in the temporal lobes (indicative of a viral infection), occipital and parietal lobes, and the cerebellum in autism. Perfusion abnormalities in these areas of the brain directly correlate with the core deficits seen in autism, and perfusion in the right cerebral hemisphere controlling functional communication, problem solving, memory, and reasoning directly correlate with symptoms seen in individuals labelled with an Asperger's diagnosis. ${ }^{100}$ Orbitofrontal hypoperfusion is seen in $\mathrm{ADHD}^{101}$ and is consistent with the challenges

\footnotetext{
${ }^{97}$ Henny Kupferstein. "Evidence of increased PTSD symptoms in autistics exposed to applied behavior analysis." (2018) Advances in Autism, Vol. 4 Issue: 1, pp.19-29, https://doi org/10.1108/AIA-08-2017-0016

${ }^{98}$ Michael Goldberg, Ismael Mena, Bruce Miller. Frontal and temporal lobe dysfunction in autism and other related disorders: ADHD and OCD. ARTÍCULO ORIGINAL 01 de julio de 1999. Clínica Las Condes, Santiago, Chile, Dept of Neurology, UCSF Medical Center, Saitovitch A, Bargiacchi A, Chabane N, et al. Social cognition and the superior temporal sulcus: implications in autism. Rev Neurol (Paris). 2012 Oct;168(10):762-70 doi: 10.1016/j.neurol.2012.07.017. Epub 2012 Sep 13, Alaerts K, Woolley DG, Steyaert J, Di Martino A, Swinnen SP, Wenderoth N. Underconnectivity of the superior temporal sulcus predicts emotion recognition deficits in autism. Social Cognitive and Affective Neuroscience. 2014;9(10):1589-1600. doi:10.1093/scan/nst156, Sasaki M. SPECT findings in autism spectrum disorders and medically refractory seizures. Epilepsy Behav. 2015 Jun;47:167-71. doi: 10.1016/j.yebeh.2014.10.033. Epub 2014 Dec 15, Ohnishi T, Matsuda $\mathrm{H}$, Hashimoto T. Abnormal regional cerebral blood flow in childhood autism. Brain. 2000 Sep;123 ( Pt 9):1838-44, Jann K, Hernandez LM, Beck-Pancer D, et al. Altered resting perfusion and functional connectivity of default mode network in youth with autism spectrum disorder. Brain and Behavior. 2015;5(9):e00358. doi:10.1002/brb3.358.

${ }^{99}$ Ryu YH, Lee JD, Yoon PH, Kim DI, Lee HB, Shin YJ. Perfusion impairments in infantile autism on technetium-99m ethyl cysteinate dimer brain single-photon emission tomography: comparison with findings on magnetic resonance imaging. Eur J Nucl Med. 1999 Mar;26(3):253-9.

${ }^{100}$ McKelvey JR, Lambert R, Mottron L, Shevell MI. Right-hemisphere dysfunction in Asperger's syndrome. J Child Neurol. 1995 Jul;10(4):310-4.

${ }^{101}$ Powell AL, Yudd A, Zee P, Mandelbaum DE. Attention deficit hyperactivity disorder associated with orbitofrontal epilepsy in a father and a son. Neuropsychiatry Neuropsychol Behav Neurol. 1997 Apr;10(2):151-4.
} 
experienced by individuals who suffer with this disorder, primarily impulsive behaviour and disinhibited emotional behavior. Moreover, areas of the brain involved with OCD symptoms, including the orbitofrontal cortex, the anterior cingulate cortex, the striatum, and the thalamus, have also been proven to be hypoperfused by NeuroSPECT. ${ }^{102}$ Altered cerebral blood flow patterns have been detected in individuals with panic disorder (with agoraphobia), OCD and PTSD and severity of symptoms correlate significantly with the level of hypoperfusion. ${ }^{103}$ Distinct hypoperfusion was detected in the frontal, parietal and temporal regions of individuals with both Alzheimer's disease and Parkinson's disease associated with dementia, and Bench et al. revealed that recovery from severe depression was associated with a significant increase in cerebral blood flow in the left dorsolateral prefrontal cortex and the medial prefrontal cortex, including the anterior cingulate. ${ }^{104}$ Hypoperfusion has also been detected in genetic disorders, suggesting that some symptoms associated with genetic disorders may be the result of microglial activation and those individuals may also benefit from treating the underlying immune dysfunction. ${ }^{105}$

Until now, brain disorders have been thought of as symptoms of a chemical imbalance in the brain or a result of underconnectivity, but the work with NeuroSPECT in autism provides clear and irrefutable evidence that the conditions we call mental disorders are symptoms of microglial activation that causes cerebral perfusion, as a result of immune dysfunction driven by alterations of the microbiome. The evidence of microglial activation in almost every health condition known to man, as noted previously, and the recovery of or improvement of symptoms in children labelled with autism, ADHD, CFS/CFIDS, etc. with corresponding spect scans showing post-treatment normalized cerebral blood flow patterns, provides further proof that the neurological issues that accompany most disease states may be treated by "de-activating" the microglia, and effectively treating chronic disease can be accomplished by removing triggers that suppress immune function while simultaneously fostering a healthy microbiome. (Figure 1)

\section{Discussion}

The consensus in autism treatment has traditionally been to load more agents into the body to treat a condition that we don't understand. The ambiguity surrounding causation has resulted in individuals with autism being subjected to a variety of questionable or proven harmful treatments such as the use of anti-psychotic medications, intensive behaviour modification, electric shock therapy, ${ }^{106}$ nicotine addiction

\footnotetext{
${ }^{102}$ Guo, Huirong, Zhao, Ning, Li, et al. Regional cerebral blood flow and cognitive function in patients with obsessive-compulsive disorder. (2014). Arquivos de Neuro-Psiquiatria, 72(1), 44-48. https://dx.doi.org/10.1590/0004-282X20130205

${ }^{103}$ Lucey JV, Costa DC, Adshead G, et al. Brain blood flow in anxiety disorders: OCD, panic disorder with agoraphobia and post traumatic stress disorder. $B r J$ Psychiatry 1997; 171:346-50

${ }^{104}$ Bench CJ, Frackowiak RS, Dolan RJ. Changes in regional cerebral blood flow on recovery from depression. Psychol Med 1995;25:247-61

${ }^{105}$ Ogura K, Fujii T, Abe N, Hosokai Y, Shinohara M, Fukuda H, Mori E. Regional cerebral blood flow and abnormal eating behavior in Prader-Willi syndrome. Brain Dev. 2013 May;35(5):427-34. doi: 10.1016/j.braindev.2012.07.013. Epub 2012 Aug 23.

${ }^{106}$ Wachtel LE, Contrucci-Kuhn SA, Griffin M, et al. ECT for self-injury in an autistic boy. Eur Child Adolesc Psychiatry. 2009;18:458-463, Wachtel LE, Kahng S, Dhossche DM, et al. ECT for catatonia in an autistic girl. Am J Psychiatry. 2008;165:329-333, Siegel M, Milligan B, Robbins D, Prentice G. Electroconvulsive therapy in an adolescent with autism and bipolar I disorder. J ECT. 2012 Dec;28(4):252-5. doi: 10.1097/YCT.0b013e31825cec86.
}

drugs, ${ }^{107}$ oral prednisolone, ${ }^{108}$ intravenous immunoglobulin therapy, ${ }^{109}$ acetylcholinesterase inhibitors, ${ }^{110}$ and a toxic African sleeping sickness drug $^{111}$ that was abandoned in HIV/AIDS treatment due to numerous deaths as a direct result of the treatment. ${ }^{112}$ There are currently over sixty ongoing interventional clinical trials with different pharmacologic approaches and more than 130 studies already completed with no drug registered as effective in treating the core symptoms of autism. ${ }^{113}$ The reason for this is simply because we have yet to administer a treatment that targets the gut and the brain simultaneously. In some cases, interventions applied independently may improve outcomes somewhat, but in terms of recovery, interventions will not be successful unless approached within a multi-component protocol.

Addressing risk factors in early life can advance opportunities for prevention, health promotion, and can also reduce a later risk for the development of chronic illness and the need for outrageously expensive behaviour therapy or a lifetime of custodial care. It is crucial that we assist these children and provide treatment as early as possible in order to increase their chances for recovery, but under the current model children are waiting years for a diagnosis, only to wait again for therapy that does not address the cause of the condition. Diet and nutrition, supplementation to replace lost essential vitamins and nutrients, and addressing the root cause of illness must be at the forefront of every medical care model, which must also combine the benefits of allopathic, naturopathic, homeopathic and traditional, or Indigenous, healing modalities. And going forward, prevention must be a paramount consideration.

The perfect storm of genetics, environment, and timing of insults early in development describes much of the chronic disease we are seeing today, but in autism only the timing is unique. The immune system does not fully develop until the age of three so we have children who are born genetically susceptible and are then exposed to massive amounts of environmental toxins. We see mothers or expectant mothers who have systemic and chronic infections (Lyme, Candida, etc.) and these infections are transferred to their babies who have no defenses to them. We then have young children with overloaded immune systems who are exposed to high doses of environmental toxins. Depending on the severity of the assault, the results could be a spectrum of illness ranging from allergies, depression, or anxiety to

\footnotetext{
${ }^{07}$ Mostafavi M, Hardy P, Arnold LE. Varenicline in Autism: Theory and Case Report of Clinical and Biochemical Changes. J Child Adolesc Psychopharmacol. 2016 Nov;26(9):792-797. Epub 2016 Apr 28.

${ }^{108}$ Shenoy S, Arnold S, Chatila T (2000) Response to steroid therapy in autism secondary to autoimmune lymphoproliferative syndrome. J Pediatr 136(5):682-687.

${ }^{109}$ Gupta S, Aggarwal S, Heads C (1996) Dysregulated immune system in children with autism: beneficial effects of intravenous immune globulin on autistic characteristics. $J$ Autism Dev Disord 26(4):439-452

${ }^{110}$ Sahu JK, Gulati S, Sapra S, Arya R, Chauhan S, Chowdhury MR, Gupta N, Kabra $\mathrm{M}$ et al (2013) Effectiveness and safety of donepezil in boys with fragile $\mathrm{X}$ syndrome: a double-blind, randomized, controlled pilot study. J Child Neurol 28(5):570-575. https:// doi.org/10.1177/0883073812449381, Handen BL, Johnson CR, McAuliffe-Bellin S, Murray PJ, Hardan AY (2011) Safety and efficacy of donepezil in children and adolescents with autism: neuropsychological measures. J Child Adolesc Psychopharmacol 21(1):43-50.

${ }^{111}$ Robert K. Naviaux, Brooke Curtis, Kefeng Li et al. Low-dose suramin in autism spectrum disorder: a small, phase I/II, randomized clinical trial. Annals of Clinical and Translational Neurology 2017; 4(7): 491-505.

112 Kaplan, Lawrence D., Wolfe, Peter R., Volberding, Paul A. et al. "Lack of response to suramin in patients with AIDS and AIDS-related complex". The American Journal of Medicine. (1987). 82 (3): 615-620. doi:10.1016/0002-9343(87)90108-2. PMID 3548350.

${ }^{113}$ Dominika Gładysz, Amanda Krzywdzińska, Kamil K. Hozyasz. Immune Abnormalities in Autism Spectrum Disorder-Could They Hold Promise for Causative Treatment? Molecular Neurobiology. August 2018, Volume 55, Issue 8, pp 6387-6435
} 


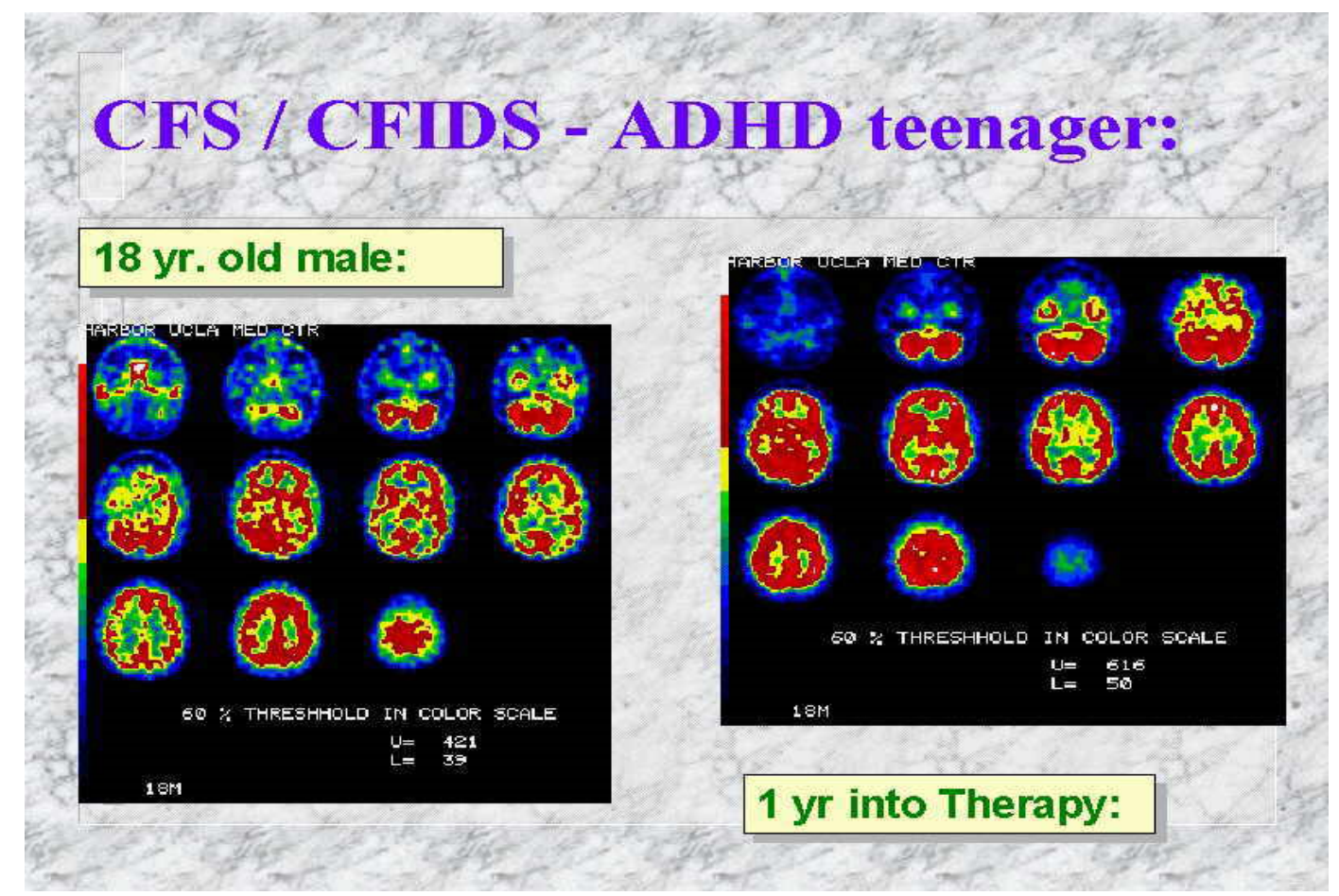

Figure 1. Michael \& Elyse Goldberg. AUTISM (“Disease, Disorder, or Syndrome?") and its Connection to ADD/ADHD, CFS/CFIDS 11/3/98

obesity, diabetes, or autism. This is all occurring during a critical period of rapid physical, emotional, and cognitive growth that is already very stressful for a little body. Brain connections are forming at a furious rate during those three years following birth. Over the past twenty-five years, in a variety of species, neuroscientists have observed that starting shortly before or after birth, the brain is the site of a fit of "synaptic exuberance", the period during development when synapse formation outstrips synapse elimination. Infant brains produce trillions more synapses than are found in mature, adult brains. In humans, this fit of synaptic exuberance is confined to the first three years of life. Most children develop autism in the second year of life (usually around eighteen months) once they start eating a standard Western diet, although this can happen much earlier or much later depending on the timing and severity of the assault. A lifestyle shift that involves preconception maternal and paternal optimization, enhanced prenatal care, and practices that support healthy immune function during the first three to five years of life, including a NIDS diet, is now imperative for fathers and mothers, but more importantly for infants and young children until the microbiome has been successfully seeded and the immune system is fully developed.

\section{Conflict of interest}

The author does not report any conflict of interest.

\section{Funding}

The author received no funding for this publication.

Copyright: (C2018 Stephenson L. This is an open-access article distributed under the terms of the Creative Commons Attribution License, which permits unrestricted use, distribution, and reproduction in any medium, provided the original author and source are credited. 